\title{
Determination of Gas-Phase Acidities of Dimethylphenols: Combined Experimental and Theoretical Study
}

\author{
Paulo J. Amorim Madeira, ${ }^{a}$ Paulo Jorge Costa, ${ }^{\mathrm{a}, *}$ \\ Maria Tereza Fernandez, José A. Martinho Simões, ${ }^{a, b}$ and \\ João Paulo Leal ${ }^{\mathrm{a}, \mathrm{c}}$ \\ ${ }^{a}$ Centro de Química e Bioquímica, Faculdade Ciências, Universidade de Lisboa, Campo Grande, Lisboa, \\ Portugal

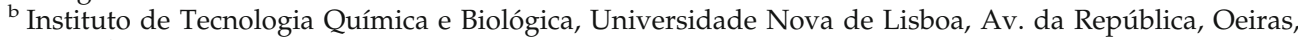 \\ Portugal \\ ${ }^{c}$ Departamento de Química, Instituto Tecnológico e Nuclear, Sacavém, Portugal
}

\begin{abstract}
The@as-phase@cidities@f(che@ix@imethylphenol@somers@ere@etermined@xperimentally, (๖y using@he@kinetic@method, Gnd@heoretically,@hrough@quantum@hemistry@alculations.CThe

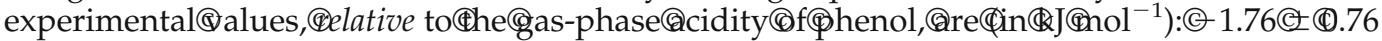

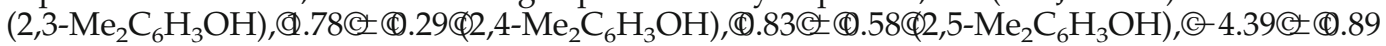

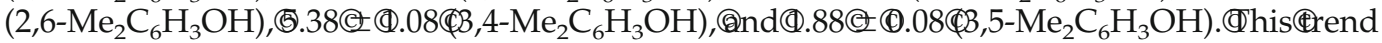
was@iscussed@y@onsidering@he@ubstituent@ffects@n@he@hermodynamic@tabilities@oth@f the@parent@phenols@and@the@corresponding@phenoxideđions.CTheCaboveCacidity@data, Cthe literature@alues@or@-,(3-,@nd@-methylphenol,@nd@he@ubstituent@ffects@nalysis@llowed@o develop@a@simple@empirical@method@to@estimate@the@acidity@of@any@methyl-substituted

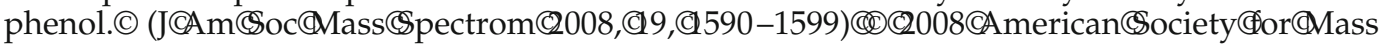
Spectrometry
\end{abstract}

A mong@he@ompounds@ith@herapeutic@properties, Cphenolic@compounds@play@an@important role@ue@to@heir@antioxidant@action,@which@is crucial@n@ighting@xidative@tress@1-4].đThe@ntioxidant@capacity@of@those@compounds@basically@derives fromథheir@bilityథo@cavenge@ery@eactive@pecies,@uch as@eroxyl@adicals@ROO).CThe@nain@nechanism@ener-

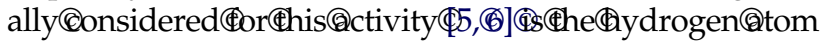
transfer(nechanism (HAT), @escribed@yबReaction@:

$$
\mathrm{ROO}^{\oplus}+\mathrm{ArOH} \rightarrow \mathrm{CROOH} @\left(\mathrm{rrO}^{\odot}\right.
$$

The@net@result@shown@in@this@reaction@can@also@be achieved@by@two@other@mechanisms, Cnamely, Csingleelectron-transfer@ollowed(by yroton@ransfer $(S E T-P T)$, Reactions $2 a-2 c$,

$$
\mathrm{ROO}^{\odot}+\mathrm{ArOH} \odot \rightarrow \mathrm{CROO}^{-}+\mathrm{ArOH}^{+\cdot \odot}
$$

$$
\mathrm{ArOH}^{+\cdot \odot} \rightarrow \mathrm{CArO}^{\cdot \odot}+\mathbb{O}^{+}
$$

Address reprint requests to Dr. J. P. Leal, Departamento de Química, Instituto Tecnológico e Nuclear, 2686-953, Sacavém, Portugal. E-mail: jpleal@itn.pt

* Present address: Departamento de Química, CICECO, Universidade de Aveiro, 3810-193, Aveiro, Portugal.

$$
\mathrm{ROO}^{-}+\circledast^{+} \rightarrow \mathrm{CROOH} \odot
$$

orゆy @@equentialథrotonథoss@lectron-transferథSPLET) [6], बReactions@3a-3c:

$$
\begin{aligned}
& \mathrm{ArOH} \odot \rightarrow\left(\mathrm{ArO}^{-}+\oplus^{+} \mathrm{H}^{(}\right) \\
& \mathrm{ArO}^{-}+\mathbb{R O O} \stackrel{\odot}{\rightarrow} \mathrm{C} \mathrm{ArO}^{\odot}+\mathbb{R O O}^{-(\mathrm{C}} \\
& \mathrm{ROO}^{-}+\mathbb{A I}^{+} \rightarrow \mathrm{CROOH} \subseteq
\end{aligned}
$$

While@he@elevant@nergetic@erm@n@heđHAT@mecha-

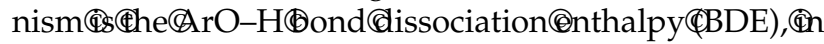
SET-PT@oneChas@to@onsider@he@ionization@energy@o ArOH@and@he@proton@affinity@PA)@of@ArO. On the other@hand, $($ he $₫$ hermochemistry@f@he@PLET@nechanism@includes@the@reaction@enthalpy@f@the@first@step (Reaction@a),@hich@orresponds@o@he@roton@ffinity (PA)@f@ArO ${ }^{-}$,@ndథhe@lectron@ffinity@f@he@henoxyl radical $($ Reaction $(3 b)$.

Since@ll@he@revious@nechanisms@ead@o@he@ame

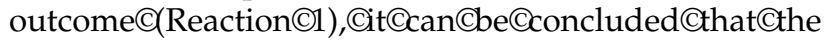
antioxidant activity of phenolic compounds is thermodynamically favored by weak $\mathrm{ArO}-\mathrm{H}$ bonds.

The ArO-H BDE, $D H^{0}(\mathrm{ArO}-\mathrm{H})$, can be determined in the gas-phase by combining the enthalpy of Reaction 3a for a given phenol, $\Delta_{\mathrm{ac}} H^{0}$, and the electron affinity, 
$E_{\mathrm{ea}}$ of the related phenoxyl radical, since the ionization energy $\left(E_{\mathrm{i}}\right)$ of the hydrogen atom is well known [7].

$$
D H^{0}(\mathrm{ArO}-\mathrm{H})=\Delta_{\mathrm{ac}} H^{0}(\mathrm{ArOH})+E_{\mathrm{ea}}(\mathrm{ArO})-E_{\mathrm{i}}(\mathrm{H})
$$

The knowledge of $\Delta_{\mathrm{ac}} \mathrm{H}^{0}(\mathrm{ArOH})$ data is also relevant for understanding the SPLET mechanism. This quantity is related to the gas-phase acidity $\Delta_{\mathrm{ac}} G^{0}(\mathrm{ArOH})$ through the relation

$$
\Delta_{\mathrm{ac}} G^{0}(\mathrm{ArOH})=\Delta_{\mathrm{ac}} H^{0}(\mathrm{ArOH})-T \Delta_{\mathrm{ac}} S^{0}(\mathrm{ArOH})
$$

The Cooks kinetic method, [8] widely applied in gasphase thermochemical measurements, was used in this work to determine $\Delta_{\mathrm{ac}} G^{0}(\mathrm{ArOH})$. It is a suitable alternative to equilibrium methods for thermochemical determinations in systems with a low vapor pressure. According to the kinetic method, the difference between the $\Delta_{\mathrm{ac}} \mathrm{H}^{0}(\mathrm{ArOH})$ values of two compounds ( $\mathrm{AH}$ and $\mathrm{BH})$ can be obtained by comparing the dissociation rates of a proton bound heterodimer $\left(\mathrm{AHB}^{-}\right)$into each individual monomers $\left(\mathrm{A}^{-}\right.$and $\left.\mathrm{B}^{-}\right)$.

$$
\mathrm{BH}+\mathrm{A}^{-} \stackrel{k_{1}}{\leftarrow} \mathrm{AHB}^{-} \stackrel{k_{2}}{\rightarrow} \mathrm{AH}+\mathrm{B}^{-}
$$

In eq $6, k_{1}$ and $k_{2}$ are the rate constants for the competitive dissociations of the dimer-anion to produce $\mathrm{A}^{-}$ and $\mathrm{B}^{-}$, respectively. The ratio

$$
\begin{aligned}
& \ln \left(k_{1} / k_{2}\right)=\ln \left[I\left(\mathrm{~A}^{-}\right) / I\left(\mathrm{~B}^{-}\right)\right] \\
& =\left[\Delta_{\mathrm{ac}} G^{0}(\mathrm{AH})-\Delta_{\mathrm{ac}} G^{0}(\mathrm{BH})\right] / R T_{\text {eff }}
\end{aligned}
$$

yields the difference between the $\Delta_{\mathrm{ac}} G^{0}$ values for the two compounds. The terms $I\left(\mathrm{~A}^{-}\right)$and $I\left(\mathrm{~B}^{-}\right)$are the abundances of both anions and $\mathrm{T}_{\text {eff }}$ is the effective temperature of the system. Combining each unknown species, $\mathrm{BH}$, with a series of compounds $\mathrm{AH}$ of known $\Delta_{\mathrm{ac}} G^{0}$, i.e., measuring $I\left(\mathrm{~A}^{-}\right)$and $I\left(\mathrm{~B}^{-}\right)$for various pairs of dimers, it is possible to calculate $\Delta_{\mathrm{ac}} G^{0}(\mathrm{BH})$. By rewriting eq 7 as

$$
\ln \left(k_{1} / k_{2}\right)=\ln \left[I\left(\mathrm{~A}^{-}\right) / I\left(\mathrm{~B}^{-}\right)\right]=m \Delta_{\mathrm{ac}} G^{0}(\mathrm{AH})-b
$$

it is seen that $\mathrm{m}=1 / R T_{\text {eff }}$ and $\mathrm{b}=\Delta_{\mathrm{ac}} G^{0}(\mathrm{BH}) / R T_{\text {eff }}$. In general, there is a good agreement between the thermochemical data obtained by the kinetic method and the values determined by other methods, such as equilibrium and bracketing [9].

The restricted kinetic method is based on the assumptions of negligible reverse activation energies, negligible entropy differences for the competitive channels, and the non-occurrence of isomeric forms of the activated dimer anion. For simple molecules (A and B) with similar backbone structure, it can be assumed that those conditions are fulfilled and therefore

$$
\begin{aligned}
& \ln \left(k_{1} / k_{2}\right)=\ln \left[I\left(\mathrm{~A}^{-}\right) / I\left(\mathrm{~B}^{-}\right)\right] \\
& =\left[\Delta_{\mathrm{ac}} H^{0}(\mathrm{AH})-\Delta_{\mathrm{ac}} H^{0}(\mathrm{BH})\right] / R T_{\text {eff }}
\end{aligned}
$$

As described above, the determination of $\Delta_{\mathrm{ac}} H^{0}(\mathrm{BH})$ for substituted phenols yields ArO-H BDEs, which allow to address some gaps (or some controversies) in the available database $[1,10]$. Most of the gas-phase acidities found in the literature were obtained for monosubstituted phenols [11, 12]. For disubstituted phenols, to the best of our knowledge, the literature is scarce. The few examples reported are relative to theoretical gas-phase acidities for dimethoxyphenols [13] and experimental values for dichlorophenol [12]. Therefore, we decided to investigate the influence of the methyl substituents on the acidity of some dimethylphenols.

\section{Experimental}

\section{Mass Spectrometry}

The experiments were performed in a Finnigan FT/MS 2001-DT FTICR mass spectrometer, equipped with a $3 T$ superconducting magnet and a Finnigan Venus Odyssey data system. The disubstituted phenols $(2,3-, 2,4-$, 2,5-, 2,6-, 3,4-, and 3,5-dimethylphenol) as well as the references were obtained commercially from SigmaAldrich and used without further purification. The reagent/collision gas used for chemical ionization $\left(\mathrm{NF}_{3}\right)$ was obtained commercially from Air Liquide with a purity grade of $100 \%$.

A certain amount of the dimethylphenol under study and the reference were placed in a glass tube and subsequently introduced into the mass spectrometer through a leak valve until the pressure reached $10^{-7}$ torr. An electron ionization (EI) mass spectrum (average of 1000 mass spectra) was acquired to ensure that both of the compounds were present in the chamber. The reagent gas was introduced by means of another leak valve until the pressure reached $10^{-6}$ torr, and a chemical ionization (CI) mass spectrum was acquired (time for CI 5-10 s, average of 5 mass spectra). $\mathrm{NF}_{3}$ undergoes dissociative electron attachment to produce $\mathrm{F}^{-}$ions, which rapidly abstract protons from the substituted phenols [7]. With this spectrum, a suitable stored waveform inverse Fourier transform (SWIFT) wave was generated to eject all the undesired ions, leaving only the heterodimer ions. A second SWIFT wave was generated to excite the isolated heterodimer ions to a trajectory radius of $0.5 \mathrm{~cm}$, which were allowed to fragment in strictly known time intervals. The spectrum obtained from each time delay was recorded as well as the relative abundances of both phenoxide ions resulting from the ionization of the dimethylphenol under study and the reference used. Incidentally, no branching ratio variation was observed in the range of the time delays used (50 $\mu \mathrm{s}-0.1 \mathrm{~s}) ; 26$ points for each system were determined. The initial and the final points were discarded and typically about 10 middle points were used to determine the average ratio, the corresponding logarithm, and the standard deviation of the mean (the uncertainty of the determination). 


\section{Computational Details}

All calculations were performed with Gaussian03 package [14]. The geometries of all the selected dimethylphenols, phenol, and respective anions were optimized without geometry constrains using the hybrid B3LYP $[15,16]$ functional with the selected basis sets (vide infra). The options OPT $=$ Tight, $\mathrm{SCF}=$ Tight and INT $=$ UltraFine were used in all geometry optimizations. Frequency calculations were performed to check the nature of the stationary points. The enthalpies at $298 \mathrm{~K}$ were obtained from eq 10,

$$
H=E_{0}+Z P E+H_{\text {trans }}+H_{\text {rot }}+H_{\text {vib }}+R T
$$

where $E_{0}$ is the electronic energy, ZPE is the zero-point energy, and $H_{\text {trans }}, H_{\text {rott }}$ and $H_{\text {vib }}$ are the translational, rotational, and vibrational contributions. $H_{\text {trans }}$ and $H_{\text {rot }}$ are $3 / 2 R T$ for a nonlinear molecule; $H_{\mathrm{vib}}$ was extracted directly form the Gaussian 03 frequency calculation output (using harmonic frequencies and moments of inertia within the rigid rotor-harmonic oscillator approximation). The last term, $R T$, stands for the $p V$ work.

\section{Results and Discussion}

\section{Mass Spectrometry}

Under the experimental conditions described above, the negative chemical ionization (CI) mass spectra of mixtures of phenols (reference $\mathrm{AH}$ and unknown $\mathrm{BH}$ ) were obtained. An example is given in Figure 1, for the mixture of 3,5-dimethylphenol $(\mathrm{MW}=122)$ and 4-methylphenol $(\mathrm{MW}=108)$. The ions at $\mathrm{m} / \mathrm{z} 215$ and 229 (Figure 1a) are the 4-methylphenol dimer anion $\left(\mathrm{AHA}^{-}\right)$and the heterodimer anion $\left(\mathrm{AHB}^{-}\right)$, respectively. The ions at $\mathrm{m} / \mathrm{z} 107$ and 121 correspond to the deprotonated 4-methylphenol and 3,5-dimethylphenol, respectively. The ions at $\mathrm{m} / \mathrm{z} 243$ correspond to the 3,5-dimethylphenol dimer anion $\left(\mathrm{BHB}^{-}\right)$.

For the same system, the $\mathrm{MS}^{2}$ mass spectrum of the isolated heterodimer $(\mathrm{m} / \mathrm{z} 229)$ obtained at the time delay of $6 \mathrm{~ms}$ is displayed in Figure 1b. The only product ions detected $(\mathrm{m} / \mathrm{z} 107$ and 121) were the deprotonated phenols, viz. the reference and 3,5dimethylphenol, respectively. Applying the kinetic
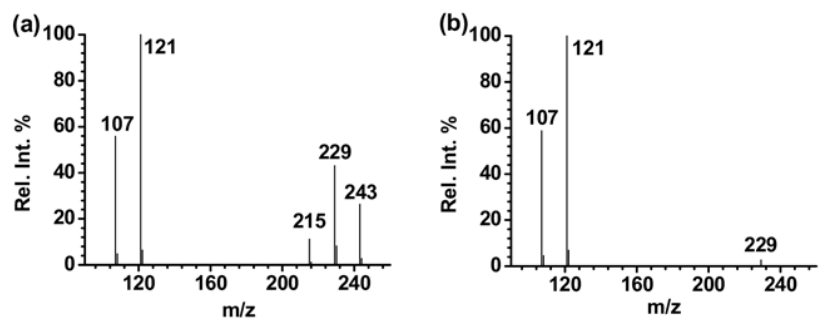

Figure 1. (a) Chemical ionization mass spectrum of a 3,5dimethylphenol and 4-methylphenol mixture. (b) $\mathrm{MS}^{2}$ mass spectrum of the isolated heterodimer $(\mathrm{m} / \mathrm{z} 229$, delay time $=6 \mathrm{~ms})$.

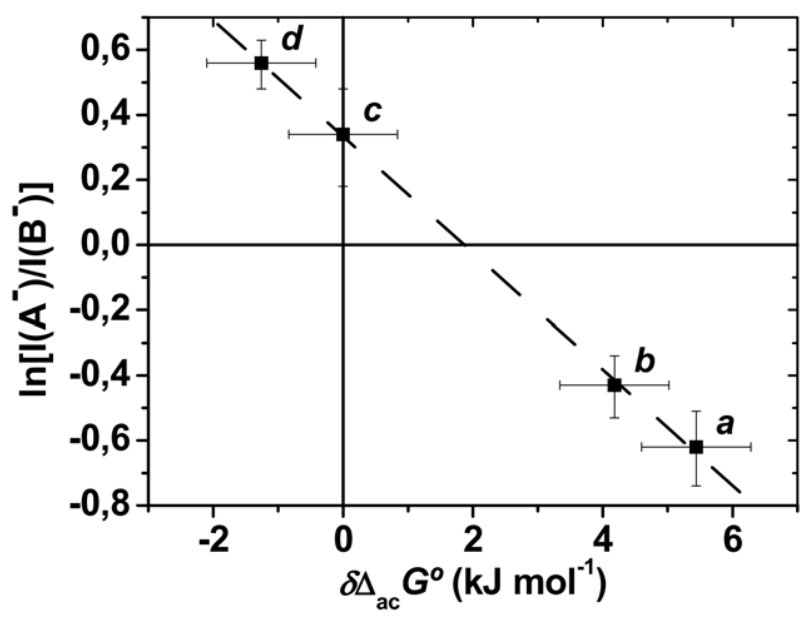

Figure 2. Representation of $\ln \left[I\left(\mathrm{~A}^{-}\right) / I\left(\mathrm{~B}^{-}\right)\right]$versus $\delta \Delta_{\mathrm{ac}} G^{0}$ (a): 3-aminophenol; (b): 4-methylphenol; (c): phenol; (d): 2-methylphenol for $\mathrm{B}^{-}=3,5$-dimethylphenol.

method as described above (eq 8), the ratios between the relative abundances of several deprotonated references and the deprotonated 3,5-dimethylphenol afforded the gas-phase acidity of 3,5-dimethylphenol. The procedure is illustrated in Figure 2, which depicts a graphical representation of $\ln \left[I\left(\mathrm{~A}^{-}\right) / I\left(\mathrm{~B}^{-}\right)\right]$versus $\delta \Delta_{\mathrm{ac}} G^{0}$ for $\mathrm{B}^{-}=3,5$-dimethylphenoxide. $\delta \Delta_{\mathrm{ac}} G^{0}$ are the $\Delta_{\mathrm{ac}} G^{0}$ values for the reference molecules (AH) relative to $\Delta_{\text {ac }} G^{0}$ of phenol, to which the value zero was assigned (Table 1). The intercept of the plot in Figure 2 allows to extract $\delta \Delta_{\text {ac }} G^{0}$ for 3,5-dimethylphenol as $1.88 \pm 0.08 \mathrm{~kJ}$ $\mathrm{mol}^{-1}$ (Table 2). The absolute values of gas-phase acidity $\left(\Delta_{\mathrm{ac}} G^{0}\right)$ and proton affinity $\left(\Delta_{\mathrm{ac}} H^{0}\right)$ of the corresponding phenoxide anion are also shown in Table 2. They rely on $\Delta_{\mathrm{ac}} G^{0}$ (phenol) $=1426 \pm 8 \mathrm{~kJ} \mathrm{~mol}^{-1}$ and $\Delta_{\mathrm{ac}} H^{0}$ (phenol) $=1454 \pm 8 \mathrm{~kJ} \mathrm{~mol}^{-1}$ [17]. As discussed above, the proton affinity was obtained under the assumption of similar $T \Delta_{\mathrm{ac}} S^{0}$ terms for 3,5-dimethylphenol and the references.

Tables 1 and 2 collect the data for the remaining dimethylphenols, obtained with the method described for 3,5-dimethylphenol. Note that when comparing the $\Delta_{\mathrm{ac}} H^{0}$ values in Table 2 , the above assumption on similar $\mathrm{T} \Delta_{\mathrm{ac}} S^{0}$ terms for each dimethylphenol and the references is replaced by another one, which is even more reasonable: The $\mathrm{T} \Delta_{\mathrm{ac}} S^{0}$ terms are constant for all the dimethylphenols. On the other hand, it must be stressed that the fairly large uncertainties displayed for $\Delta_{\mathrm{ac}} G^{0}$ and $\Delta_{\mathrm{ac}} H^{0}$ result from the uncertainties in the anchors. The uncertainties associated with the trends of these quantities are a fraction of a kilojoule.

To understand the values in Table 2 it is necessary to bear in mind that the effects of the substituents on the acidity are determined by the relative stability of the phenoxide anions and by the stability of the corresponding neutral phenols. To rationalize the substituent effects on the acidity of the dimethylphenols under study, it is convenient to recall the more simple methylphenols, namely 2-, 3-, and 4-methylphenol, for which 
Table 1. Values of $\ln \left[I\left(\mathrm{~A}^{-}\right) / I\left(\mathrm{~B}^{-}\right)\right]\left(\mathrm{B}^{-}\right.$dimethylphenol anion; $\mathrm{A}^{-}$reference anion)

\begin{tabular}{|c|c|c|c|c|c|c|c|}
\hline \multicolumn{2}{|c|}{ References $(\mathrm{AH})$} & \multicolumn{6}{|c|}{ Dimethylphenols $(\mathrm{BH})$} \\
\hline & $\delta \Delta_{\mathrm{ac}} G^{0 \mathrm{a}}$ & $2,3-$ & $2,4-$ & $2,5-$ & $2,6-$ & $3,4-$ & $3,5-$ \\
\hline 4-Fluorophenol & -9.62 & 1.21 & & 1.58 & 0.93 & & \\
\hline 2-Methylphenol & -1.26 & & 1.12 & 0.51 & -0.33 & 1.79 & 0.56 \\
\hline Phenol & 0.00 & -0.51 & 0.43 & 0.04 & -0.98 & 0.96 & 0.34 \\
\hline 4-Isopropylphenol & 1.67 & -0.41 & 0.05 & -0.20 & -1.17 & 0.82 & \\
\hline 4-Methylphenol & 4.60 & -0.83 & -0.91 & & & 0.26 & -0.43 \\
\hline 3-Aminophenol & 5.44 & & - & & & -0.01 & -0.62 \\
\hline Linear fit equation: $y=$ & & $-0.15 x-0.26$ & $-0.33 x+0.59$ & $-0.15 x+0.13$ & $-0.19 x-0.81$ & $-0.23 x+1.25$ & $-0.18 x+0.34$ \\
\hline $\mathrm{R}^{2}$ & & 0.97 & 0.98 & 0.97 & 0.97 & 0.92 & 1.00 \\
\hline
\end{tabular}

${ }^{\mathrm{a}} \delta \Delta_{\mathrm{ac}} G^{0}\left(\mathrm{~kJ} \mathrm{~mol}{ }^{-1}\right)$ are the $\Delta_{\mathrm{ac}} G^{0}(\mathrm{AH})$ values relative to $\Delta_{\mathrm{ac}} G^{0}$ (phenol) and were taken from reference [12]. Each value is considered to be affected by a standard error of $0.84 \mathrm{~kJ} \mathrm{~mol}^{-1}$. The linear fit equation was determined by the least-squares method.

the relative gas-phase acidities were reported as $-1.26 \pm$ $0.84 \mathrm{~kJ} \mathrm{~mol}^{-1}, 1.67 \pm 0.84 \mathrm{~kJ} \mathrm{~mol}^{-1}$, and $4.60 \pm 0.84 \mathrm{~kJ}$ $\mathrm{mol}^{-1}$, respectively $[11,12,18]$. These data, together with the $\Delta_{\mathrm{ac}} G^{0}$ values from Table 2, are depicted in Figure 3. The acidity trend in the methylphenols can be better understood with Figure 4, which displays the stabilities of the neutral phenols and their phenoxides, as measured by their enthalpies of formation [19].

As indicated by their Hammett parameters, methyl groups are electron donors both by resonance and inductive effects $[1,20]$. Hydroxyl groups, on the other hand, are electron donors by resonance effect but electron acceptors by inductive effect. The most stable isomer in the methylphenol triad is therefore 3methylphenol (Figure 4) because only in this case there is a cooperative behavior of the two groups. The least stable isomer, on the other hand, should be either 2- or 4-methylphenol because in these positions both groups are electron donors. The fact that 2-methylphenol is some $1.4 \mathrm{~kJ} \mathrm{~mol}^{-1}$ more stable that 4-methylphenol is probably due to a small attractive interaction between the neighbor $\mathrm{CH}_{3}$ and $\mathrm{OH}$ groups in the ortho-isomer.

The stability trend in Figure 4 for the methylphenoxide anions shows that the most stable species is now 2-methylphenoxide. The meta-isomer should still be the most stable on the basis of electron donating/accepting ability of the substituents. The extra stability of the ortho-isomer must be due to a significant strengthening of the attractive interaction between the neighbor $\mathrm{CH}_{3}$ and $\mathrm{O}^{-}$groups on the 2-methylphenoxide.

Table 2. Experimental $\delta \Delta_{\text {ac }} G^{0}$ values determined from eq 8 and the data in Table 1. Absolute values of $\Delta_{\mathrm{ac}} G^{0}$ and $\Delta_{\mathrm{ac}} H^{0}$ $\left(\mathrm{kJ} \mathrm{mol}^{-1}\right)$ are also shown

\begin{tabular}{lrcc}
\hline Dimethylphenol & \multicolumn{1}{c}{$\delta \Delta_{\mathrm{ac}} G_{\exp }^{0}{ }^{\mathrm{a}}$} & \multicolumn{1}{c}{$\Delta_{\mathrm{ac}} G^{0}$} & \multicolumn{1}{c}{$\Delta_{\mathrm{ac}} H^{0}$} \\
\hline \hline $2,3-$ & $-1.76 \pm 0.76$ & $1424.2 \pm 8.0$ & $1452.2 \pm 8.0$ \\
$2,4-$ & $1.78 \pm 0.29$ & $1427.8 \pm 8.0$ & $1455.8 \pm 8.0$ \\
$2,5-$ & $0.83 \pm 0.58$ & $1426.8 \pm 8.0$ & $1454.8 \pm 8.0$ \\
$2,6-$ & $-4.39 \pm 0.89$ & $1421.6 \pm 8.0$ & $1449.6 \pm 8.0$ \\
$3,4-$ & $5.38 \pm 1.08$ & $1431.4 \pm 8.1$ & $1459.4 \pm 8.1$ \\
$3,5-$ & $1.88 \pm 0.08$ & $1427.9 \pm 8.0$ & $1455.9 \pm 8.0$ \\
\hline
\end{tabular}

aEach uncertainty represents the standard deviation of the mean from ca. 10 independent experiments.
The previous discussion allows understanding the acidity trend of the methylphenols (Figure 4). The same type of reasoning can also be used to discuss the data for the six isomers of dimethylphenol, displayed in Figure 5. For instance, it is observed that the most unstable isomers, 3,4- and 2,3-dimethylphenol, are the only ones having a repulsive interaction between vicinal $\mathrm{CH}_{3}$ groups. Fine details of the trend are hindered by the uncertainty intervals assigned to the gas-phase enthalpies of formation (typically $1 \mathrm{~kJ} \mathrm{~mol}^{-1}$ ) [21]. For instance, the values for the most stable compounds (2,4-, 3,5-, 2,6-, and 2,5-dimethylphenol) fall within a 2

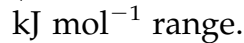

With regard to the dimethylphenoxides, the most stable is the 2,6- isomer, where two attractive interactions between the methyl groups and the oxygen can be established, followed by 2,4- and 2,5-dimethylphenoxide, which have only one $\mathrm{O}^{-} \ldots \mathrm{CH}_{3}$ attractive interaction

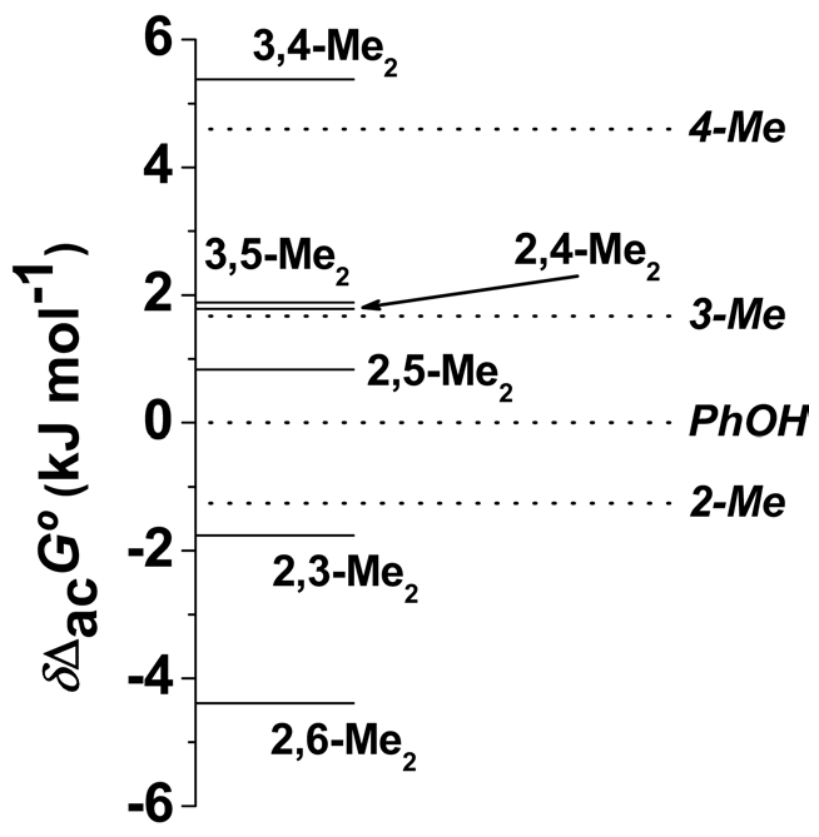

Figure 3. Gas-phase acidities of dimethylphenols and methylphenols (dotted lines) relative to the acidity of phenol. 


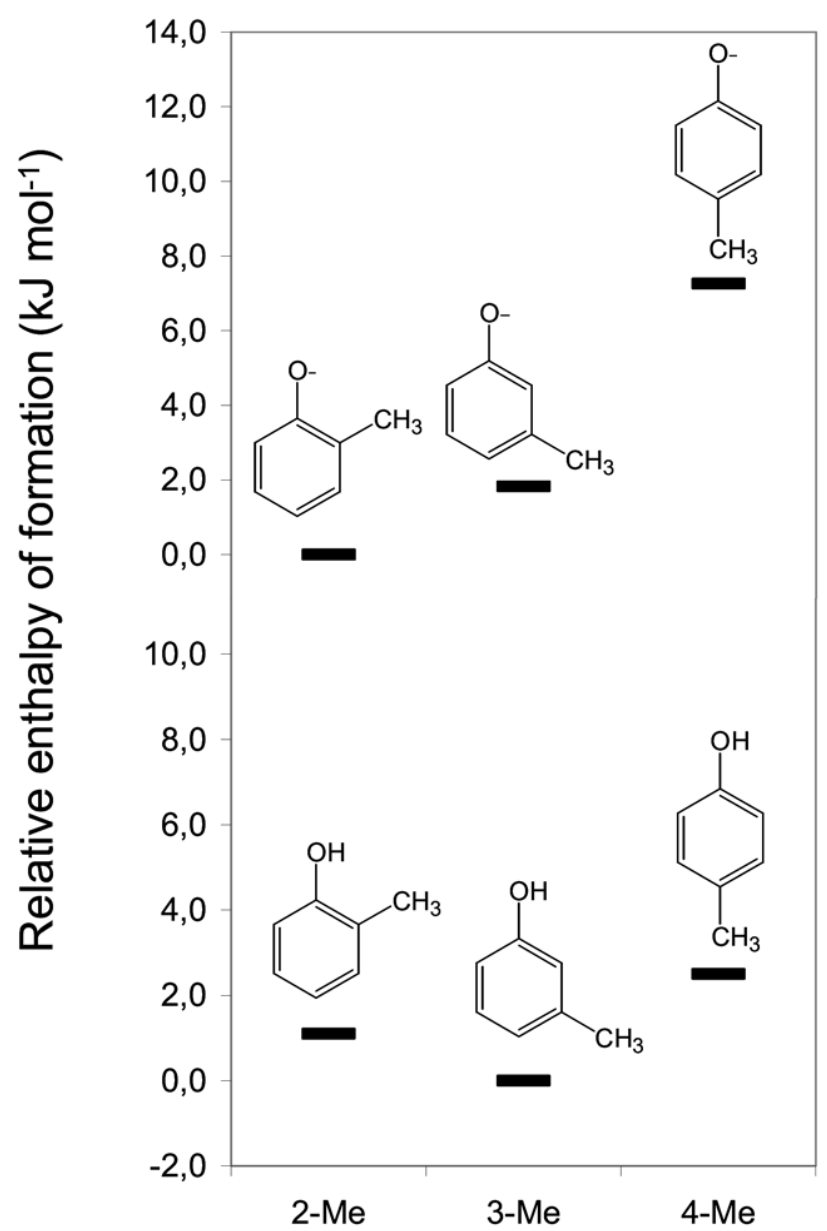

Figure 4. Relative enthalpies of formation of methylphenols and methylphenoxides $\left(\mathrm{kJ} \mathrm{mol}^{-1}\right)$. A zero value was assigned to the enthalpy of formation of the most stable isomer. The enthalpies of formation of the phenoxides were obtained from the enthalpies of formation of the parent phenols (reference [19]) and the corresponding acidities (see text).

and have no repulsive interaction between vicinal $\mathrm{CH}_{3}$ groups. On the other hand, the most unstable isomer is 3,4-dimethylphenoxide: It has no stabilizing interaction between methyl groups and oxygen, only one of the methyl substituents stabilizes the anion, and there is a repulsive interaction between the $\mathrm{CH}_{3}$ groups.

Aiming to find a simple way of estimating the acidities of methyl-substituted phenols, we have incorporated the above ideas into an empirical equation that attempts to fit the data for methyl- and dimethylpenols:

$$
\delta \Delta_{\mathrm{ac}} G^{0}=x \mathrm{Z}_{\mathrm{CC}}+a \mathrm{Z}_{\mathrm{CO}}+b P_{\text {ortho }}+c P_{\text {meta }}+d P_{\text {para }}
$$

Here $Z_{\mathrm{cc}}$ and $Z_{\mathrm{co}}$ represent interactions between vicinal groups. The former result from the interactions between neighboring methyl groups, whose number is equal to $x$. For instance, in 3,4- and 2,3-dimethylphenol, $x=1$; in 2,3,4,5-tetramethylphenol, $x=3$. The need of the second parameter, $Z_{\mathrm{co}}$, results from the fact that, for example in 2,6-dimethylphenol, the $\mathrm{OH}$ group interacts differently with each one of the vicinal methyl groups ( $a=1$ when there are two ortho methyl groups and $a=0$ in all other cases). The three remaining terms in eq 11 represent the contributions of methyl groups at different positions. Each one of the parameters $b, c$, and $d$ can be equal to zero or one. A value of one means that at least one methyl group is present at the corresponding position. For instance, in the case of 2,4-dimethylphenol $b=1$, $c=0$, and $d=1$; for 3,5-dimethylphenol $b=0, c=1$, and $d=0$; for 2,3,4,5-tetramethylphenol $b=1, c=1$, and $d=1$.

The values of $Z_{\mathrm{cc}}, Z_{\mathrm{co}}, P_{\text {ortho, }} P_{\text {meta }}$, and $P_{\text {para }}$ were obtained from a multilinear regression of the acidities of phenol, methylphenols, and dimethylphenols. The quality of fit is shown in Table 3 and in Figure 6. The estimated uncertainty associated with the predictions using the multilinear fit is ca. $0.6 \mathrm{~kJ} \mathrm{~mol}^{-1}$. The average deviation for all the phenols considered is $0.4 \mathrm{~kJ} \mathrm{~mol}^{-1}$

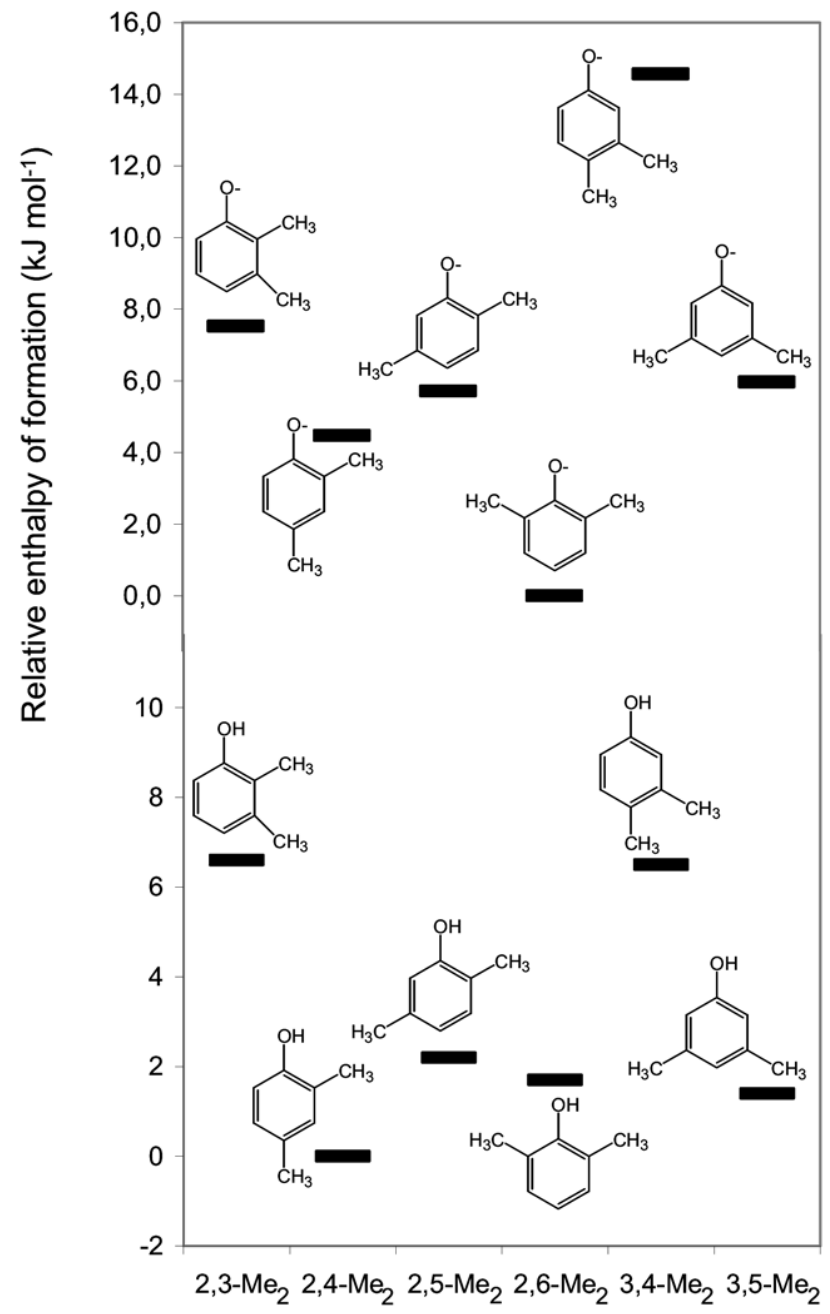

Figure 5. Relative enthalpies of formation of methylphenols and methylphenoxides $\left(\mathrm{kJ} \mathrm{mol}^{-1}\right)$. A zero value was assigned to the enthalpy of formation of the most stable isomer. The enthalpies of formation of the phenoxides were obtained from the enthalpies of formation of the parent phenols (reference [21]) and the corresponding acidities (see text). 
Table 3. Experimental and predicted $\delta \Delta_{\mathrm{ac}} G^{0}$ values $\left(\mathrm{kJ} \mathrm{mol}^{-1}\right)$ for several phenols

\begin{tabular}{lrcc}
\hline \multicolumn{1}{c}{ Compound } & Predicted $^{\mathrm{a}}$ & Experimental $^{\mathrm{b}}$ & $\begin{array}{c}\text { Absolute } \\
\text { deviation }^{2}\end{array}$ \\
\hline \hline $\mathrm{PhOH}$ & 0.00 & 0.00 & 0.00 \\
$2-\mathrm{MeC}_{6} \mathrm{H}_{4} \mathrm{OH}$ & -1.85 & $-1.26 \pm 0.84^{\mathrm{c}}$ & 0.59 \\
$3-\mathrm{MeC}_{6} \mathrm{H}_{4} \mathrm{OH}$ & 2.08 & $1.67 \pm 0.84^{\mathrm{c}}$ & 0.41 \\
$4-\mathrm{MeC}_{6} \mathrm{H}_{4} \mathrm{OH}$ & 4.35 & $4.60 \pm 0.84^{\mathrm{c}}$ & 0.25 \\
$2,3-\mathrm{Me}_{2} \mathrm{C}_{6} \mathrm{H}_{3} \mathrm{OH}$ & -1.29 & $-1.76 \pm 0.76$ & 0.47 \\
$2,4-\mathrm{Me}_{2} \mathrm{C}_{6} \mathrm{H}_{3} \mathrm{OH}$ & 2.50 & $1.78 \pm 0.29$ & 0.72 \\
$2,5-\mathrm{Me}_{2} \mathrm{C}_{6} \mathrm{H}_{3} \mathrm{OH}$ & 0.23 & $0.83 \pm 0.58$ & 0.60 \\
$2,6-\mathrm{Me}_{2} \mathrm{C}_{6} \mathrm{H}_{3} \mathrm{OH}$ & -4.39 & $-4.39 \pm 0.89$ & 0.00 \\
$3,4-\mathrm{Me}_{2} \mathrm{C}_{6} \mathrm{H}_{3} \mathrm{OH}$ & 4.91 & $5.38 \pm 1.08$ & 0.47 \\
$3,5-\mathrm{Me}_{2} \mathrm{C}_{6} \mathrm{H}_{3} \mathrm{OH}$ & 2.08 & $1.88 \pm 0.08$ & 0.20 \\
\hline
\end{tabular}

${ }^{a}$ Calculated from equation 11 with $Z_{\mathrm{cc}}=-1.5167, Z_{\mathrm{co}}=-2.5411, P_{\text {ortho }}=$ $-1.8489, P_{\text {meta }}=2.0763$, and $P_{\text {para }}=4.3498$.

bThis work, unless stated otherwise.

'Values from reference [12].

and in most cases the deviation is smaller than the experimental error involved.

The application of eq 11 to predict the acidities of other polymethylphenols is presented in Table 4 . These results indicate that the introduction of additional methyl groups does not lead to acidities that are significantly different from those observed for dimethylphenols (only 2,3,5,6-tetramethylphenol is predicted to be more acidic than 2,6-dimethylphenol and none is predicted to be less acidic than 3,4-dimethylphenol). To our knowledge, the only experimental value reported for a polymethylphenol is for 2,4,6-trimethylphenol [22]. The relative acidity value measured for this compound is $\delta \Delta_{\mathrm{ac}} G^{0}=0$, in excellent agreement with the estimated value in Table $4\left(-0.04 \mathrm{~kJ} \mathrm{~mol}^{-1}\right)$.

\section{Quantum-Chemical Calculations}

As phenol and the phenoxide anion are used as references in this work, it is important to discuss their structures. Table 5 shows the most relevant interatomic distances calculated at the B3LYP level of theory for those two species, compared with experimental values

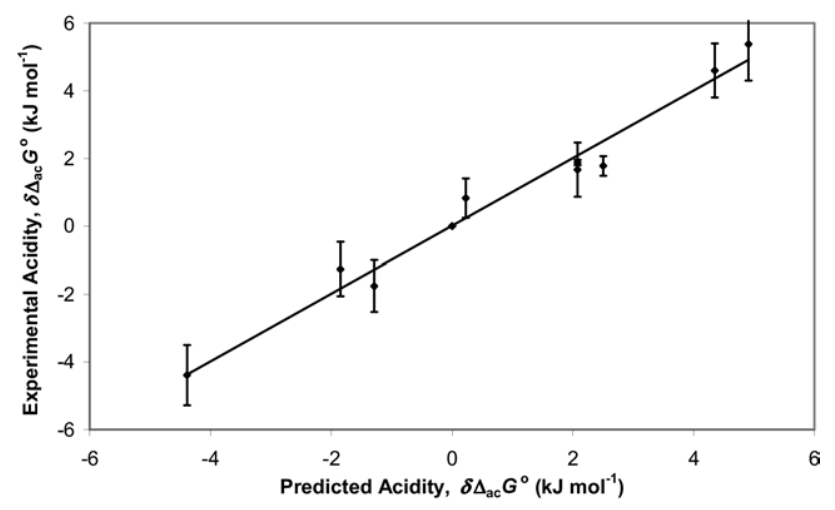

Figure 6. Predicted versus experimental $\delta \Delta_{\mathrm{ac}} G^{0}$ values (experimental error bars are shown); $y=(1.00 \pm 0.06) x+(0.01 \pm 0.16)$; $\mathrm{R}^{2}=0.97$.
Table 4. Estimated $\delta \Delta_{\mathrm{ac}} G^{0}$ values for methylphenols (kJ mol$\left.{ }^{-1}\right)$

\begin{tabular}{lc}
\hline \multicolumn{1}{c}{ Compound } & Estimated value $^{\mathrm{a}}$ \\
\hline \hline $2,3,4-\mathrm{Me}_{3} \mathrm{C}_{6} \mathrm{H}_{2} \mathrm{OH}$ & 1.54 \\
$2,3,5-\mathrm{Me}_{3} \mathrm{C}_{6} \mathrm{H}_{2} \mathrm{OH}$ & -1.29 \\
$2,3,6-\mathrm{Me}_{3} \mathrm{C}_{6} \mathrm{H}_{2} \mathrm{OH}$ & -3.83 \\
$2,4,5-\mathrm{Me}_{3} \mathrm{C}_{6} \mathrm{H}_{2} \mathrm{OH}$ & 3.06 \\
$2,4,6-\mathrm{Me}_{3} \mathrm{C}_{6} \mathrm{H}_{2} \mathrm{OH}$ & -0.04 \\
$3,4,5-\mathrm{Me}_{3} \mathrm{C}_{6} \mathrm{H}_{2} \mathrm{OH}$ & 3.39 \\
$2,3,4,5-\mathrm{Me}_{4} \mathrm{C}_{6} \mathrm{H}_{1} \mathrm{OH}$ & 0.03 \\
$2,3,4,6-\mathrm{Me}_{4} \mathrm{C}_{6} \mathrm{H}_{1} \mathrm{OH}$ & -1.00 \\
$2,3,5,6-\mathrm{Me}_{4} \mathrm{C}_{6} \mathrm{H}_{1} \mathrm{OH}$ & -5.35 \\
$2,3,4,5,6-\mathrm{Me}_{5} \mathrm{C}_{6} \mathrm{OH}$ & -4.03 \\
\hline
\end{tabular}

${ }^{\mathrm{a} C a l c u l a t e d}$ from eq 11 with $Z_{\mathrm{cc}}=-1.5167, Z_{\mathrm{co}}=-2.5411, P_{\text {ortho }}=$ $-1.8489, P_{\text {meta }}=2.0763$, and $P_{\text {para }}=4.3498$.

for phenol [23] and phenoxide [24, 25]. High-level ab-initio calculations (MRCI/6-31+G*) for phenoxide, taken from the literature, are also shown [26]. Atom labeling is presented in Scheme $\mathbf{1}$.

The structure of phenol is not a challenge for B3LYP functional and it is no surprise that it yields excellent results for ground state geometries. The same conclusion was also reached by Wright and coworkers [27]. In fact, several papers have reported the calculated gasphase structures of phenol as well as the structures of several monosubstituted phenols using different quality basis sets with success [28, 29]. With a computational "low-cost" standard basis set, such as $6-31 G(d)$, the average deviation of our calculated distances from the experimental data is very small $(0.005 \AA)$. On the other hand, Bakalbassis et al. [29] have proposed that optimum results are obtained with the unconventional $6-31+G(, 3 p d)$ basis set in a series of compounds such as phenol, 2-hydroxyphenol, and 2-methoxyphenol. Therefore, we also report calculated distances at the B3LYP/6-31+G(,3pd) level of theory. The small discrepancies of our values with the ones reported by Bakalbassis et al. may be due to the use of a tighter integration grid and SCF convergence criteria in our calculations. The average deviation is also small $(0.010$ $\AA ̊$ ), although larger than for B3LYP/6-31G(d). In fact, the $6-31+G(, 3 p d)$ basis set slightly overestimates the $\mathrm{C}-\mathrm{C}$ and $\mathrm{C}-\mathrm{O}$ bond lengths.

Structural information for the phenolate anion can also be found in the literature, especially after the controversy about the character of the $\mathrm{C}-\mathrm{O}^{-}$bond. It has been suggested in 1997 that DFT fails for the phenolate anion, yielding $\mathrm{C}-\mathrm{O}^{-}$bonds that are too short in comparison with the experimental value, taken to be $1.4 \AA$ [30]. Later, Suter and Nonella [26] refuted this idea, showing that even using highly correlated methods, the calculated $\mathrm{C}-\mathrm{O}^{-}$bond length does not exceed 1.3 $\AA$. The $\mathrm{C}^{-} \mathrm{O}^{-}$distance computed at the B3LYP/6-31G(d) theory level is $1.266 \AA$, consistent with a considerable double-bond character in phenoxide and in keeping with the $\mathrm{MRCI} / 6-31+\mathrm{G}^{*}$ result $(1.277 \AA)$. With the $6-31+\mathrm{G}(, 3 \mathrm{pd})$ basis set, the calculated $\mathrm{C}-\mathrm{O}^{-}$ 
Table 5. B3LYP-calculated distances ( $\AA$ ) for phenol and phenoxide compared with experimental values. $\mathrm{MRCI} / 6-31+\mathrm{G}^{*}$ values for phenoxides are also shown for comparison

\begin{tabular}{|c|c|c|c|c|c|c|c|c|}
\hline & \multicolumn{3}{|c|}{$\mathrm{PhOH}$} & \multicolumn{5}{|c|}{$\mathrm{PhO}^{-}$} \\
\hline & $6-31 \mathrm{G}(\mathrm{d})$ & $6-31+G(, 3 p d)$ & $\operatorname{Exp}^{a}$ & $6-31 G(d)$ & $6-31+G(, 3 p d)$ & $\mathrm{MRCl} / 6-31+\mathrm{G}(\mathrm{d})^{\mathrm{b}}$ & Exp $1^{\mathrm{c}}$ & Exp2 ${ }^{d}$ \\
\hline $\mathrm{O}-\mathrm{H}$ & 0.970 & 0.966 & 0.957 & & & & & \\
\hline $\mathrm{C} 1-\mathrm{O}$ & 1.369 & 1.402 & 1.375 & 1.266 & 1.307 & 1.277 & 1.317 & 1.331 \\
\hline $\mathrm{C} 1-\mathrm{C} 2$ & 1.399 & 1.399 & 1.391 & 1.452 & 1.445 & 1.441 & 1.408 & 1.399 \\
\hline $\mathrm{C} 2-\mathrm{C} 3$ & 1.393 & 1.399 & 1.392 & 1.388 & 1.396 & 1.394 & 1.385 & 1.380 \\
\hline C3-C4 & 1.398 & 1.403 & 1.395 & 1.405 & 1.411 & 1.405 & 1.370 & 1.387 \\
\hline C4-C5 & 1.395 & 1.401 & 1.395 & 1.404 & 1.411 & 1.405 & 1.385 & 1.376 \\
\hline C5-C6 & 1.396 & 1.402 & 1.394 & 1.388 & 1.396 & 1.394 & 1.397 & 1.374 \\
\hline $\mathrm{C} 6-\mathrm{C} 1$ & 1.399 & 1.400 & 1.391 & 1.451 & 1.445 & 1.441 & 1.378 & 1.415 \\
\hline error $^{\mathrm{e}}$ & 0.005 & 0.010 & & $0.033^{f}$ & $0.028^{f}$ & & & \\
\hline & & & & $0.032^{\mathrm{g}}$ & $0.028^{\mathrm{g}}$ & & & \\
\hline
\end{tabular}

a Values from reference [23]

balues from reference [26].

'Values from the crystal structure of tetra- $n$-butylammonium phenolate [24].

dValues from the crystal structure of sodium phenolate [25].

eAverage deviation from experimental points $(\AA ̊)$.

${ }^{\mathrm{f}}$ Average deviation from Exp 1.

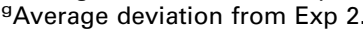

distance is $1.307 \AA$, in good agreement with the X-ray experimental values. However, the $\mathrm{X}$-ray structures correspond to phenolate salts with $\mathrm{O}^{-} \ldots \mathrm{H}-\mathrm{O}$ or $\mathrm{O}^{-} \ldots \mathrm{Na}^{+}$bonds. These contacts have been shown to elongate the $\mathrm{C}-\mathrm{O}^{-}$bond compared with the free phenoxide anion [26].

Figure 7 displays the computed bond lengths for the dimethylphenols and the comparison of these values with experimental data for 2,3-, 2,5-, 2,6-, and 3,4dimethylphenol [31-33]. The agreement is very good, the average deviations from experimental points being less than $\sim 0.02 \AA$ with the $6-31 \mathrm{G}(\mathrm{d})$ and $6-31+\mathrm{G}(, 3 \mathrm{pd})$ basis sets. It is expected that the quality of the optimized geometries of 2,4- and 3,5-dimethylphenol is similar. This allows the conclusion that both B3LYP/631G(d) and B3LYP/6-31+G(,3pd) methods provide reliable geometries to be used in the subsequent thermochemical calculations.

No comparison with experimental data for the anions can be made, and we must assume that both methods provide reliable optimized structures, as concluded for the phenoxide anion. One point worth mentioning is the fact that the $\mathrm{C}-\mathrm{O}^{-}$bonds are systematically shorter with the $6-31 \mathrm{G}(\mathrm{d})$ basis set than with the $6-31+\mathrm{G}(, 3 \mathrm{pd})$ basis set. This was already observed for $\mathrm{PhO}^{-}$.

The calculated $\Delta_{\mathrm{ac}} H^{0}$ results for the dimethylphenols are collected in Table 6. Although our main goal is<smiles>Oc1ccccc1</smiles><smiles>CCc1c(C)cccc1O</smiles>

phenol 2,3-dimethylphenol<smiles>Cc1ccc(O)c(C)c1</smiles>

2,4-dimethylphenol<smiles>CCc1ccc(C)cc1O</smiles>

2,5-dimethylphenol<smiles>Cc1cccc(C)c1O</smiles>

2,6-dimethylphenol<smiles>Cc1ccc(O)cc1C</smiles>

3,4-dimethylphenol

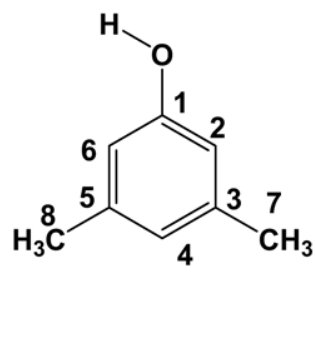

3,5-dimethylphenol

Scheme 1 

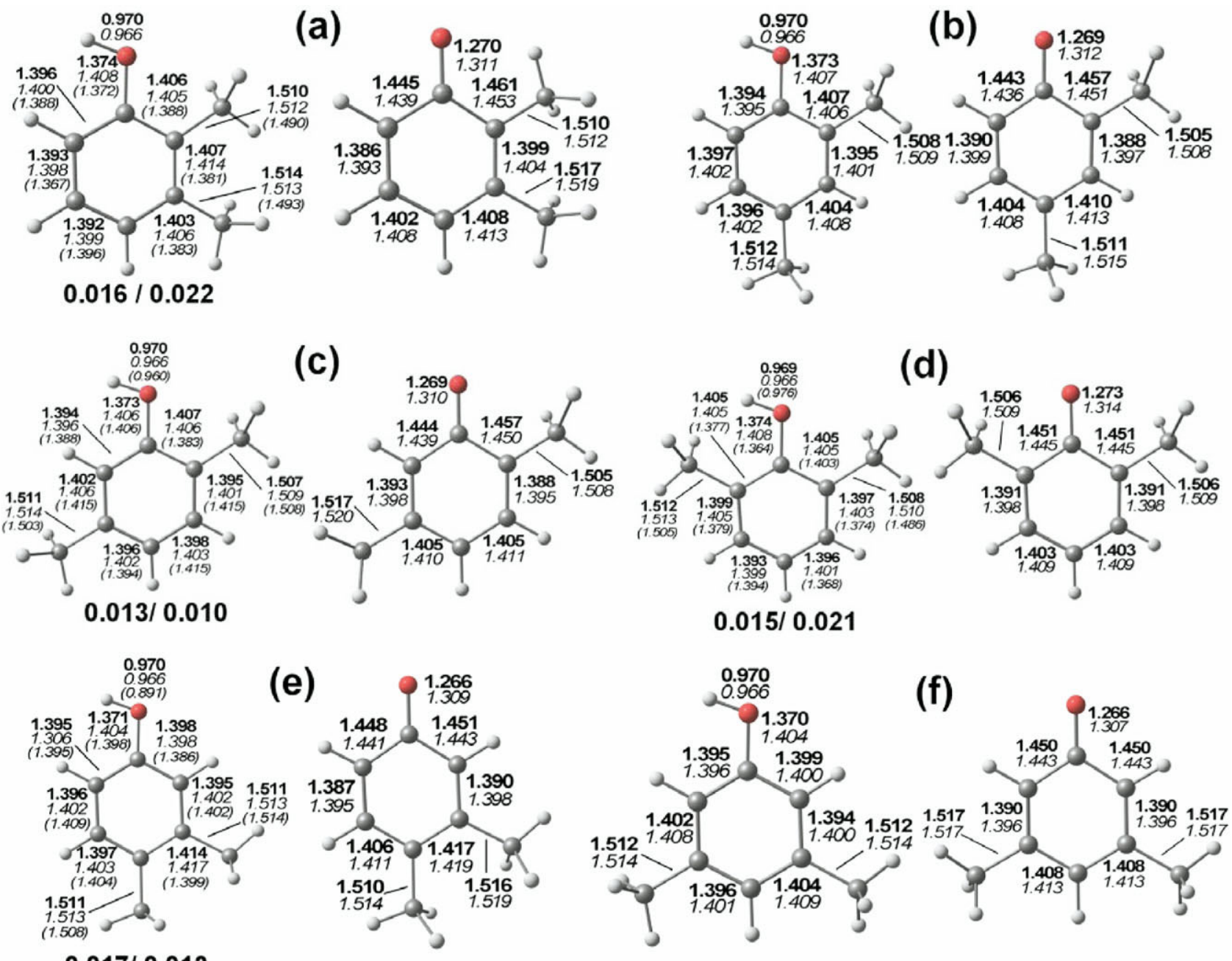

$0.017 / 0.013$

Figure 7. Selected B3LYP-calculated distances (Å) for 2,3-dimethylphenol (a), 2,4-dimethylphenol (b), 2,5-dimethylphenol (c), 2,6-dimethylphenol (d), 3,4-dimethylphenol (e), 3,5-dimethylphenol (f), and respective anions. The values computed with the basis set $6-31 G(d)$ and $6-31+G(, 3 p d)$ are shown in bold and italics, respectively. X-ray experimental values, when available, are in parenthesis. Average deviations from experimental points $(\AA)$ are also shown below the structures for $6-31 G(d)$ and $6-31+\mathrm{G}(, 3 \mathrm{pd})$ basis sets, respectively.

comparing the $\Delta_{\text {ac }} H^{0}$ values relative to phenol $\left(\delta_{\mathrm{ac}} H^{0}\right)$, it is worth to note that the B3LYP/6-311+G(2d,2p) value $\left(1456 \mathrm{~kJ} \mathrm{~mol}^{-1}\right)$ is in excellent agreement with the selected $\Delta_{\text {ac }} H^{0}$ for phenol [17]. The remaining methods yield results that are at variance with the experimental value.

Table 6. Calculated and experimental $\Delta_{\mathrm{ac}} H^{0}$ and $\delta \Delta_{\mathrm{ac}} H^{0}$ values $\left(\mathrm{kJ} \mathrm{mol}^{-1}\right)$ for the dimethylphenols ${ }^{\mathrm{a}}$

\begin{tabular}{lcccc}
\hline \multicolumn{1}{c}{ Compound } & B3LYP 6-31G(d) & B3LYP 6-31+G(,3pd) & B3LYP 6-311+G(2d,2p) & Exp $^{\mathrm{b}}$ \\
\hline \hline $\mathrm{PhOH}$ & $1493.2(0.0)$ & $1471.3(0.0)$ & $1455.6(0.0)$ & $1454^{\mathrm{d}}(0.0)$ \\
$2,3-\mathrm{Me}_{2} \mathrm{C}_{6} \mathrm{H}_{3} \mathrm{OH}$ & $1487.2(-6.0)$ & $1471.8(0.5)$ & $1456.0(0.5)$ & $1452.2(-1.8)$ \\
$2,4-\mathrm{Me}_{2} \mathrm{C}_{6} \mathrm{H}_{3} \mathrm{OH}$ & $1489.3(-3.9)$ & $1474.4(3.1)$ & $1459.4(3.8)$ & $1455.8(1.8)$ \\
$2,5-\mathrm{Me}_{2} \mathrm{C}_{6} \mathrm{H}_{3} \mathrm{OH}$ & $1489.1(-4.1)$ & $1471.0(-0.3)$ & $1456.0(0.4)$ & $1454.8(0.8)$ \\
$2,6-\mathrm{Me}_{2} \mathrm{C}_{6} \mathrm{H}_{3} \mathrm{OH}$ & $1481.2(-12.0)$ & $1465.8(-5.5)$ & $1450.5(-5.1)$ & $1449.6(-4.4)$ \\
$3,4-\mathrm{Me}_{2} \mathrm{C}_{6} \mathrm{H}_{3} \mathrm{OH}$ & $1495.7(2.5)$ & $1478.8(7.5)$ & $1463.8(8.2)$ & $1459.4(5.4)$ \\
$3,5-\mathrm{Me}_{2} \mathrm{C}_{6} \mathrm{H}_{3} \mathrm{OH}$ & $1489.0(-4.2)$ & $1475.0(3.7)$ & $1460.1(4.5)$ & $1455.9(1.9)$ \\
Average error & 5.2 & 1.6 & 1.8 & \\
\hline
\end{tabular}

${ }^{\mathrm{a}} \delta \Delta_{\mathrm{ac}} H^{0}$ values (in parenthesis) are relative to $\Delta_{\mathrm{ac}} H^{0}$ of phenol.

${ }^{\mathrm{b}}$ Computed using the optimized geometry, $\triangle Z P E$, and $\Delta H_{\text {vib }}$ calculated at the B3LYP/6-31G(d) theory level.

'This work; data from Table 2.

${ }^{d}$ Experimental value derived from energy-resolved competitive collision-induced dissociation methods (reference 17).

${ }^{\mathrm{e}}$ Average deviation of $\delta \Delta_{\mathrm{ac}} H^{0}$ from experimental values. 
With regard to the relative data, it is observed in Table 6 that the average error for B3LYP/6-31G(d) $(5.2$ $\mathrm{kJ} \mathrm{mol}^{-1}$ ) is larger than the magnitude of the calculated $\delta \Delta_{\mathrm{ac}} H^{0}$ values. On the other hand, the B3LYP/6$311+\mathrm{G}(2 \mathrm{~d}, 2 \mathrm{p})$ and B3LYP/6-31+G(,3pd) approaches afford very good results, with average errors of $1.8 \mathrm{~kJ}$ $\mathrm{mol}^{-1}$ and $1.6 \mathrm{~kJ} \mathrm{~mol}^{-1}$, respectively. The experimental acidity trend, viz. 2,6 $>2,3>\mathrm{PhOH}>2,5>2,4>3,5$ $>3,4$ is satisfactorily reproduced by the results obtained with the unconventional $6-31+\mathrm{G}(, 3 \mathrm{pd})$ basis set, except for the fact that 2,5- and 2,3-dimethylphenol have "switched" positions. The calculated value for the relative acidity of 2,3-dimethylphenol $\left(0.5 \mathrm{~kJ} \mathrm{~mol}^{-1}\right)$ is underestimated relative to the experimental value $(-1.8$ $\mathrm{kJ} \mathrm{mol}^{-1}$ ) while for 2,5-dimethylphenol, the predicted value $\left(-0.3 \mathrm{~kJ} \mathrm{~mol}^{-1}\right)$ is overestimated. This method actually predicts that the 2,3 and the 2,5 isomers and phenol have similar acidities, a feature that is also predicted using B3LYP/6-311+G(2d,2p). In this case the trend is $2,6>\mathrm{PhOH} \approx 2,5 \approx 2,3>2,4>3,5>3,4$.

The theoretical results seem to support, in general, the acidity scale determined experimentally by the kinetic method. There appears to be little doubt that 2,6-dimethylphenol is the most acidic compound and that 3,4-dimethylphenol is the least acidic one, followed by 3,5- and 2,4-dimethylphenol, respectively. Some doubts arise in the relative order of 2,5- and 2,3dimethylphenol. The experimental relative acidities are $0.8 \mathrm{~kJ} \mathrm{~mol}^{-1}$ and $-1.76 \mathrm{~kJ} \mathrm{~mol}^{-1}$, respectively, showing that 2,3-dimethylphenol is more acidic than phenol. The small discrepancies between experimental and theoretical data may result from the deficient evaluation of the thermal vibrational corrections due to the presence of low-vibrational modes in these species, specially in 2,3-dimethylphenol where there are three substituents in vicinal positions.

\section{Conclusions}

The experimental gas-phase acidity trend of the six dimethylphenol isomers can be understood by analyzing the substituent effects on the thermodynamic stabilities of the parent phenols and the corresponding phenoxide ions. The experimental trend is generally in keeping with the data computed from quantum chemistry methods. The substituent effects can be incorporated into a simple empirical model that allows estimating the acidity of any methyl-substituted phenol. The prediction was checked, for the only available case, and proved to be remarkably correct.

\section{Acknowledgments}

The authors acknowledge support for this work by FCT, POCI, and FEDER through the project POCI/QUI/58,925/2004. PJC thanks FCT for a post-doctoral grant (SFRH/BPD/27,082/2006). PJAM thanks FCT for a Ph.D. grant (SFRH/BD/27,614/2006).

\section{References}

1. Santos, R. M. B.; Martinho Simões, J. A. Energetics of the O-H Bond in Phenol and Substituted Phenols: A Critical Evaluation of Literature Data. J. Phys. Chem. Ref. Data 1998, 27, 707-739.

2. Jovanovic, S. V.; Steenken, S.; Simic, M. G.; Hara, Y. Antioxidant Properties of Flavonoids: Reduction Potentials and Electron Transfer Reactions of Flavonoid Radicals. In Flavonoids in Health and Disease, Rice-Evans, C. A.; Packer, L., Eds.; Marcel Dekker: New York, 1998; pp. 137.

3. Halliwell B.; Gutteridge, J. M. C. Free Radicals in Biology and Medicine; Oxford University Press: Oxford, 1999, and references therein

4. Wright, J. S.; Johnson, E. R.; DiLabio, G. A. Predicting the Activity of Phenolic Antioxidants: Theoretical Method, Analysis of Substituent Effects, and Application to Major Families of Antioxidants. J. Am. Chem. Soc. 2001, 123, 1173-1183, and references therein.

5. Klein, E.; Lukeš, V. DFT/B3LYP Study of the Substituent Effect on the Reaction Enthalpies of the Individual Steps of Sequential Proton Loss Electron Transfer Mechanism of Phenols Antioxidant Action: Correlation with Phenolic C-O Bond Length. J. Mol. Struct. Theochem. 2007, 805, 153-160, and references therein.

6. Musialik, M.; Litwinienko, G. Scavenging of DPPH Center Dot Radicals by Vitamin E is Accelerated by Its Partial Ionization: The Role of Sequential Proton Loss Electron Transfer. Org. Lett. 2005, 7, 4951-4954.

7. Ervin, K. M. Experimental Techniques in Gas-Phase Ion Thermochemistry. Chem. Rev. 2001, 101, 391-444.

8. Cooks, R. G.; Wong, P. S. H. Kinetic Method of Making Thermochemical Determinations: Advances and Applications. Acc. Chem. Res. 1998, 31, 379-386.

9. Harrison, A. G. The Gas-Phase Basicities and Proton Affinities of Amino Acids and Peptides. Mass Spectrom. Rev. 1997, 16, 201-217.

10. Silva, M. R.; Matos, M. A.; Miranda, M.; Sousa, M. H.; Santos, R. M. B.; Martinho Simões, J. A. Standard Enthalpies of Formation of 2,6-di-tertButyl-4-Methylphenol and 3,5-di-tert-Butylphenol and Their Phenoxy Radicals. Struct. Chem. 2001, 12, 171-181.

11. McMahon, T. B.; Kebarle, P. Intrinsic Acidities of Substituted Phenols and Benzoic Acids Determined by Gas-Phase Proton-Transfer Equilibria. J. Am. Chem. Soc. 1977, 99, 2222-2230.

12. Fujio, M.; McIver, R. T.; Taft, R. W. Effects on the Acidities of Phenols from Specific Substituent-Solvent Interactions-Inherent Substituent Parameters from Gas-Phase Acidities. J. Am. Chem. Soc. 1981, 103, 4017-4029.

13. Matos, M. A. R.; Miranda, M. S.; Morais, V. M. F. Thermochemical Study of the Methoxy- and Dimethoxyphenol Isomers. J. Chem. Eng. Data 2003, $48,669-679$.

14. Frisch, M. J.; Trucks, G. W.; Schlegel, H. B.; Scuseria, G. E.; Robb, M. A.; Cheeseman, J. R.; Zakrzewski, V. G.; Montgomery, J. A. Jr.; Stratmann, R. E.; Burant, J. C.; Dapprich, S.; Millam, J. M.; Daniels, A. D.; Kudin, K. N.; Strain, M. C.; Farkas, O.; Tomasi, J.; Barone, V.; Cossi, M.; Cammi, R.; Mennucci, B.; Pomelli, C.; Adamo, C.; Clifford, S.; Ochterski, J.; Petersson, G. A.; Ayala, P. Y.; Cui, Q.; Morokuma, K.; Malick, D. K.; Rabuck, A. D.; Raghavachari, K.; Foresman, J. B.; Cioslowski, J.; Ortiz, J. V.; Stefanov, B. B.; Liu, G.; Liashenko, A.; Piskorz, P.; Komaromi, I. Gomperts, R.; Martin, R. L.; Fox, D. J.; Keith, T.; Al-Laham, M. A.; Peng, C. Y.; Nanayakkara, A.; Gonzalez, C.; Challacombe, M.; Gill, P. M. W.; Johnson, B. G.; Chen, W.; Wong, M. W.; Andres, J. L.; Head-Gordon, M.; Replogle, E. S.; Pople, J. A. Gaussian03; Gaussian Inc.: Wallingford, CT, 2004.

15. Lee, C.; Yang, W.; Parr, R. G. Development of the Colle-Salvetti Correlation-energy formula into a functional of the electron-density. Phys. Rev. B 1988, 37, 785-789.

16. Becke, A. D. Density-Functional Thermochemistry. 3. The Role of Exact Exchange. J. Chem. Phys. 1993, 98, 5648-5652.

17. Angel, L. A.; Ervin, K. M. Competitive Threshold Collision-Induced Dissociation: Gas-Phase Acidity and O-H Bond Dissociation Enthalpy of Phenol. J. Phys. Chem. A 2004, 108, 8346-8352.

18. Linstrom, P. J.; Mallard, W. G. Eds., NIST Chemistry WebBook, NIST Standard Reference Database Number 69, June 2005, National Institute of Standards and Technology: Gaithersburg MD (http://webbook.nist. gov).

19. Richard, L. S.; Bernardes, C. E. S.; Diogo, H. P.; Leal, J. P.; Minas. da Piedade, M. E. Energetics of Cresols and of Methylphenoxyl Radicals. J. Phys. Chem. A 111, 2007, 8741-8748.

20. Johnson, C. D. The Hammett Equation; Cambridge University Press: Cambridge, 1980

21. Pedley, J. B. Thermochemical Data and Structures of Organic Compounds; Thermodynamics Research Center Data Series, Vol I; Thermodynamics Research Center: College Station, 1994.

22. Angel, L. A.; Ervin, K. M. Gas-Phase Acidities and O-H Bond Dissociation Enthalpies of Phenol, 3-Methylphenol, 2,4,6-Trimethylphenol, and Ethanoic Acid. J. Phys. Chem. A 2006, 110, 10392-10403.

23. Larsen, N. W. Microwave Spectra of the 6 Mono-c-13-Substituted Phenols and of Some Mono-Deuterated Species of Phenol-Complete Substitution Structure and Absolute Dipole Moment. J. Mol. Struct. 1979, 51, 175-190.

24. Goddard, R.; Herzog, H. M.; Reetz, M. T. Cation-Anion CH ... OInteractions in the Metal-Free Phenolate, Tetra- $n$-Butylammonium Phenol-Phenolate. Tetrahedron 2002, 58, 7847-7850. 
25. Sieler, J.; Pink, M.; Zahn, G. The Structures of Two Hydrates of Sodium Phenoxide $-\mathrm{C}_{6} \mathrm{H} 5 \mathrm{ONa} \cdot \mathrm{H}_{2} \mathrm{O}$ and $\mathrm{C}_{6} \mathrm{H}_{5} \mathrm{ONa} \cdot 3 \mathrm{H}_{2} \mathrm{O}$. Z. Anorg. Allg. Chem. 1994, 620, 743-748.

26. Suter, H. U.; Nonella, M. A. Quantum Chemical Investigation of the C-O Bond Length and Stretching Mode of the Phenolate Anion. J. Phys. Chem. A 1998, 102, 10128-10133.

27. Wright, J. S.; Carpenter, D. J.; McKay, D. J.; Ingold, K. U. Theoretical Calculation of Substituent Effects on the O-H Bond Strength of Phenolic Antioxidants Related to Vitamin E. J. Am. Chem. Soc. 1997, 119, 4245-4252.

28. Klein, E.; Lukeš, V. DFT/B3LYP Study of O-H Bond Dissociation Enthalpies of Para- and Meta-Substituted Phenols: Correlation with the Phenolic C-O Bond Length. I. Mol. Struct. Theochem. 2006, 767, 43-50.

29. Bakalbassis, E. G.; Lithoxoidou, A. T.; Vafiadis, A. P. Theoretical Calculation of Accurate Absolute and Relative Gas- and LiquidPhase O-H Bond Dissociation Enthalpies of 2-Mono- and 2,6-
Disubstituted Phenols, Using DFT/B3LYP. J. Phys. Chem. A 2003, 107, $8594-8606$

30. Nwobi, O.; Higgins, J.; Zhou, X.; Liu, R. Density Functional Calculation of Phenoxyl Radical and Phenolate Anion: An Examination of the Performance of DFT Methods. Chem. Phys. Lett. 1997, 272, $155-161$.

31. Neuman, A. Gillier-Pandraud, $\mathrm{H}$. Crystalline Structures of 2,3 Dimethylphenol and 2,5-Dimethylphenol at $150^{\circ} \mathrm{C}$. Acta Crystallogr. B Struct. Crystallogr. Cryst. Chem. 1973, 29, 1017-1023.

32. Antona, D.; Longchambon, F.; Vandenborre, M. T.; Becker, P. Structure of Dimethyl-2,6 Phenol. Acta Crystallogr. B Struct. Crystallogr. Cryst. Chem. 1973, 29, 1372-1376.

33. Vandenborre, M. T.; Gillier-Pandraud, H.; Antona, D.; Becker, P. Structure of 3,4-dimethylphenol at $-130^{\circ} \mathrm{C}$. Acta Crystallogr. B Struct. Crystallogr. Cryst. Chem. 1973, 29, 2488-2492. 